\title{
Utilization of Construction Waste Composite Powder Materials as Cementitious Materials in Small-Scale Prefabricated Concrete
}

\author{
Cuizhen Xue, Aiqin Shen, Yinchuan Guo, and Tianqin He \\ Road and Railway Engineering, Chang'an University, Xian 710064, China \\ Correspondence should be addressed to Cuizhen Xue; xuecuizhen2008@163.com
}

Received 17 May 2016; Accepted 3 July 2016

Academic Editor: Stevulova Nadezda

Copyright (C) 2016 Cuizhen Xue et al. This is an open access article distributed under the Creative Commons Attribution License, which permits unrestricted use, distribution, and reproduction in any medium, provided the original work is properly cited.

The construction and demolition wastes have increased rapidly due to the prosperity of infrastructure construction. For the sake of effectively reusing construction wastes, this paper studied the potential use of construction waste composite powder material (CWCPM) as cementitious materials in small-scale prefabricated concretes. Three types of such concretes, namely, C20, C25, and $\mathrm{C} 30$, were selected to investigate the influences of CWCPM on their working performances, mechanical properties, and antipermeability and antifrost performances. Also the effects of CWCPM on the morphology, hydration products, and pore structure characteristics of the cement-based materials were analyzed. The results are encouraging. Although CWCPM slightly decreases the mechanical properties of the $\mathrm{C} 20$ concrete and the $7 \mathrm{~d}$ compressive strengths of the C25 and C 30 concretes, the $28 \mathrm{~d}$ compressive strength and the $90 \mathrm{~d}$ flexural strength of the C25 and C30 concretes are improved when CWCPM has a dosage less than $30 \%$; CWCPM improves the antipermeability and antifrost performances of the concretes due to its filling and pozzolanic effects; the best improvement is obtained at CWCPM dosage of 30\%; CWCPM optimizes cement hydration products, refines concrete pore structure, and gives rise to reasonable pore size distribution, therefore significantly improving the durability of the concretes.

\section{Introduction}

The construction and demolition wastes have increased rapidly due to the prosperity of infrastructure construction in China. According to China Strategic Alliance of Technological Innovation for Construction Waste Recycling Industry, 1.5 billion tons of construction wastes was generated across the whole country in 2012 [1]. It was also predicted that, by 2020 , the quantity of construction wastes will reach up to 5 billion tons [2]. Moreover, approximately $30 \% \sim 50 \%$ of the construction wastes are bricks $[3,4]$. Although recycling of construction wastes has been promoted in order to reduce the huge quantity of the wastes and to protect the environment, large amounts of wastes, such as waste bricks, are still piled up in the suburbs due to very low utilization rate in China, causing negative impacts on environment and increasing concerns in local communities. Therefore, looking for highly effective reutilization ways for the construction wastes has become a pressing issue.

In recent years, reusing waste bricks as civil engineering materials has been brought into effect. Studies have shown that the waste brick is mostly composed of silica and alumina, part of which are in unstable amorphous states [5]. This means that the waste brick is a kind of pozzolanic materials and exhibits some degree of activity. It is well recognized that the pozzolanic materials can improve long-term strength and durability of cement concrete [6,7]. A number of scholars have evaluated the potential of directly using crushed bricks as aggregates in concrete and road base. However, some of them indicated that the crushed bricks as aggregates sharply reduced the mechanical performances of concrete $[8,9]$, which limits the utilization rate of the construction waste bricks. On the other hand, using waste bricks as cementitious materials in mortar and cement concrete has shown better outcomes. Naceri and Hamina indicated that brick powder improved the grinding time and setting times of cement, and it also increased the mechanical strengths of cement mortar when the substitution rate was 10\% [10]. Kavas and Olgun demonstrated that the setting times of cement paste decreased with the increase of waste brick dosage due to the high water absorption of the waste brick [11]. Wild also demonstrated that the ground brick can substitute part of 
TABLE 1: Chemical composition of CWBP.

\begin{tabular}{lccccccccc}
\hline Components & $\mathrm{CaO}$ & $\mathrm{SiO}_{2}$ & $\mathrm{Al}_{2} \mathrm{O}_{3}$ & $\mathrm{Fe}_{2} \mathrm{O}_{3}$ & $\mathrm{MgO}$ & $\mathrm{K}_{2} \mathrm{O}$ & $\mathrm{Na}_{2} \mathrm{O}$ & $\mathrm{SO}_{3}$ & $\mathrm{LOI}$ \\
\hline Content (wt\%) & 1.13 & 49.3 & 17.9 & 2.92 & 1.66 & 2.09 & - & 0.11 & 3.5 \\
\hline
\end{tabular}

cement; when the replacement levels were 10 and 20\%, the 90 d's strength of concrete was close to the control concrete [12]. A study by Chen et al. showed that recycled brick powder can be used as mineral filler in the asphalt mixture, and the mixtures prepared with recycled brick powder had better mechanical properties than the reference mixtures [13]. O'Farrell et al. stated that because of the pozzolanic nature of ground brick the long-term strength of the concrete was increased [14]. Lin et al. studied the pozzolanic characteristics of brick powder through cement paste; the results showed that the brick powder can be regarded as strong pozzolanic materials and replace part of cement [15]. Wild et al. studied the pozzolanic activities of several types of ground bricks, showing that all the ground brick types had potential activities and could be utilized as cement in mortar and concrete [16].

Researches such as the abovementioned have generally paid attention to the activity of the brick powder and its potential use in cement mortar and concrete. In comparison, limited investigations have been carried out to stimulate the low activities of the brick or brick powder through an effective way. Some studies attempted to reheat the waste brick and then ground it to certain fineness in order to increase its activity [17]. However, this not only increases cost but also consumes significant amount of energy and releases large quantity of $\mathrm{CO}_{2}$ [18]. Therefore, to effectively recycle and utilize waste bricks in a sustainable and environmentally friendly way, new method that does not require reheating waste bricks should be used. This can be achieved by mixing the construction waste brick powder (CWBP) together with fly ash, mineral powder, and alkali-activator to synthesize construction waste composite powder material (CWCPM), since the superimposed effect, complementary effect, and synergic effect between these components can dramatically improve the activity of the brick powder, as will be shown later.

This paper studied the working performances, mechanical properties, and antipermeability and antifrost performances of small-scale prefabricated concretes with CWCPM used as cementitious material replacing some portion of cement. Microstructural studies were also conducted on cement pastes with and without CWCPM to analyze the improvement mechanism of CWCPM on cement-based materials. This experimental work presents a new way to reuse construction waste bricks, and the results can provide theoretical and practical bases for effectively recycling waste bricks, both in China and across the world.

\section{Materials and Experimental Methods}

2.1. Materials. The following materials were used: cement: 42.5 ordinary Portland cement with apparent density of $3.112 \mathrm{~g} / \mathrm{cm}^{3}$ and surface area of $365 \mathrm{~m}^{2} / \mathrm{kg}$; coarse aggregate:

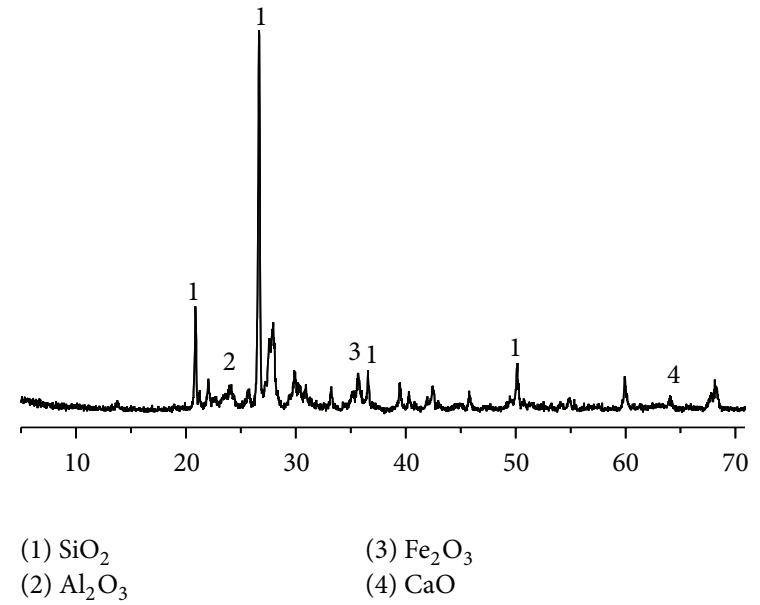

FIGURE 1: XRD result of CWBP.

$20 \mathrm{~mm}$ crushed gravel; fine aggregate: river sand with fineness modulus of 2.48; water: tap water.

CWBP was obtained from building demolition, through classifying, crushing, milling, and sieving. CWBP owns a specific surface area of $450 \mathrm{~m}^{2} / \mathrm{kg}$. The chemical composition and X-ray diffraction (XRD) results of CWBP are presented in Table 1 and Figure 1, respectively, which show that the main components of CWBP are quartz $\left(\mathrm{SiO}_{2}\right)$ and aluminum oxide $\left(\mathrm{Al}_{2} \mathrm{O}_{3}\right)$.

Chemical titration test indicated that the contents of active $\mathrm{SiO}_{2}$ and $\mathrm{Al}_{2} \mathrm{O}_{3}$ in CWBP were $10.18 \%$ and $4.73 \%$, respectively. The results of mortar strength test showed that 28 d's compressive strength ratio was $61.3 \%$ when the CWBP dosage was $40 \%$. This means that CWBP is not an inert material but has low activity.

In order to improve the activity of CWBP, previous research synthesized CWCPM, which consists of $25 \mathrm{wt} \%$ CWBP, $25 \mathrm{wt} \%$ fly ash, $50 \mathrm{wt} \%$ mineral powder, and alkaliactivator, through a variety of technical ways (Hao Zhang, personal communication, 2015). The chemical compositions of mineral powder and fly ash are shown in Table 2; their specific surface areas are 362 and $420 \mathrm{~m}^{2} / \mathrm{kg}$, respectively. The CWCPM used as cement and concrete admixture is required to meet certain standards, which are shown in Table 3; also shown are the corresponding measured values. Table 4 shows the chemical composition of CWCPM. Figures 2 and 3 show the particle morphologies of CWBP and CWCPM, respectively, by scanning electron micrograph (SEM).

Tables 3 and 4 indicate that CWCPM has high specific surface area $\left(415 \mathrm{~m}^{2} / \mathrm{kg}\right)$ and contains significant amount of $\mathrm{CaO}$ of $21.7 \sim 25.5 \%$. Figures 2 and 3 illustrate that CWBP has an uneven particle distribution and its particles have sharp edges, whereas CWCPM owns a reasonable particle size distribution and its particles are mainly round and subround 
TABLE 2: Chemical compositions of mineral powder and fly ash.

\begin{tabular}{lccccccccc}
\hline Components & $\mathrm{SiO}_{2}$ & $\mathrm{CaO}$ & $\mathrm{Al}_{2} \mathrm{O}_{3}$ & $\mathrm{Na}_{2} \mathrm{O}$ & $\mathrm{SO}_{3}$ & $\mathrm{MgO}$ & $\mathrm{Fe}_{2} \mathrm{O}_{3}$ & $\mathrm{MnO}_{2}$ & $\mathrm{~K}_{2} \mathrm{O}$ \\
\hline Mineral powder (wt\%) & 40.20 & 40.20 & 10.5 & 0.23 & 5.13 & 4.36 & - & 0.14 & - \\
Fly ash (wt\%) & 51.54 & 4.48 & 32.08 & 0.76 & 0.65 & 1.035 & 6.84 & - & 1.61 \\
\hline
\end{tabular}

TABLE 3: Physical properties of CWCPM.

\begin{tabular}{lccccc}
\hline & $\begin{array}{c}\text { Standard consistency } \\
\text { water }(\%)\end{array}$ & $\begin{array}{c}\text { Loss on } \\
\text { ignition }(\%)\end{array}$ & $\begin{array}{c}\text { Density } \\
\left(\mathrm{kg} / \mathrm{m}^{3}\right)\end{array}$ & $\begin{array}{c}\text { Specific surface } \\
\operatorname{area}\left(\mathrm{m}^{2} / \mathrm{kg}\right)\end{array}$ & $\begin{array}{c}\text { Particle size }(\mu \mathrm{m}) \\
\text { Required value }\end{array}$ \\
Measured value & $<1.0 \%$ & $<5 \%$ & $2 \sim 3$ & $>300$ & $5 \sim 16$ \\
\hline
\end{tabular}

TABLE 4: Chemical composition of CWCPM.

\begin{tabular}{lcccc}
\hline Components & $\mathrm{CaO}$ & $\mathrm{Al}_{2} \mathrm{O}_{3}$ & $\mathrm{Fe}_{2} \mathrm{O}_{3}$ & $\mathrm{SiO}_{2}$ \\
\hline Content (wt\%) & $21.7 \sim 25.5$ & $15.8 \sim 18.5$ & $2.6 \sim 4$ & $42.5 \sim 37.5$ \\
\hline
\end{tabular}

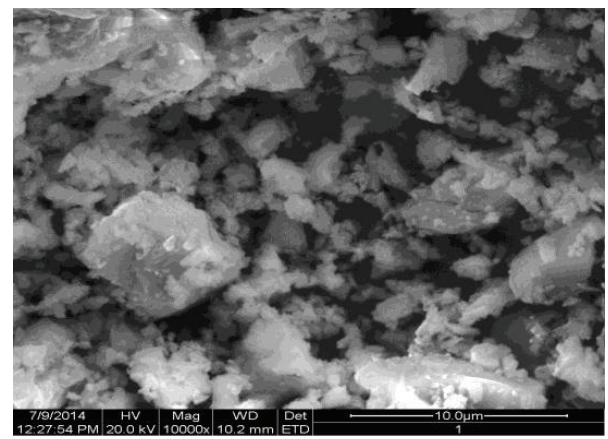

Figure 2: The SEM image of CWBP.

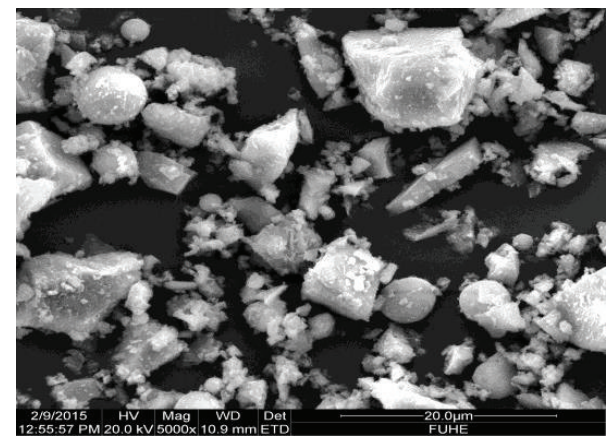

FIgURE 3: The SEM image of CWCPM.

and contain a considerable amount of tiny beads. Therefore, CWCPM has higher activity than CWBP.

Compressive strength test conducted on cement mortars with and without CWCPM indicated that the $7 \mathrm{~d}$ and $28 \mathrm{~d}$ compressive strength ratios (the ratio of the compressive strength of cement mortar with CWCPM to that of cement mortar without CWCPM) reached $97.9 \%$ and $112.4 \%$, respectively, when the dosage of CWCPM was $40 \%$ (i.e., the weight of CWCPM was $40 \%$ of the weight of cement). The reason is that the mineral powder has a good early strength effect, the fly ash has good water reduction and late strength effects, and the CWBP has good filling effect. Hence, the complementary effects of these components can exert positive impacts on cement mortars. In addition, the alkaliactivator can maintain a suitable alkalinity condition, which insures the volcanic ash effect of CWCPM on the cement mortar.

Furthermore, compared to cement, CWCPM has lower production cost and amount of $\mathrm{CO}_{2}$ emissions, showing that using CWCPM to substitute some portion of cement in concrete engineering can be a cost-effective and environmentally friendly way to recycle construction waste bricks.

\subsection{Experimental Methods}

2.2.1. Macroscopic Experimental Methods. The small-scale prefabricated concretes used in pavement engineering are generally low strength concretes. Three kinds of low strength concretes, that is, C20, C25, and C30, were selected in this paper to study the influences of CWCPM on concrete performances. The reference mix ratios of each kind of concrete, which means that no CWCPM was incorporated (CWCPM dosage was $0 \%$ ), were obtained through orthogonal test, as shown in Table 5.

Based on the reference mix ratios, this paper studied the influences of different CWCPM dosages (i.e., replacing 20\%, $30 \%$, and $40 \%$ of the cement by weight, resp.) on the working performance, mechanical strengths, and antipermeability and antifrost performances of the selected C20, C25, and C30 concretes. Compressive strength tests were conducted on $7 \mathrm{~d}$ and $28 \mathrm{~d}$ cured specimens with dimensions of $100 \mathrm{~mm} \times$ $100 \mathrm{~mm} \times 100 \mathrm{~mm}$, and flexural strength tests were on $90 \mathrm{~d}$ cured specimens with dimensions of $100 \mathrm{~mm} \times 100 \mathrm{~mm} \times$ $400 \mathrm{~mm}$. Antipermeability and antifrost tests were carried out by adopting rapid chloride migration (RCM) method and rapid freeze-thaw method, respectively, all specimens were cured $28 \mathrm{~d}$ under standard conditions (temperature: $20 \pm$ $2{ }^{\circ} \mathrm{C}$, relative humidity: $>95 \%$ ), and the test procedures are described clearly elsewhere [19]. For antifrost performance test, two different types of freeze-thaw mediums, that is, water and $\mathrm{NaCl}$ solution, were used. Water freeze-thaw test was conducted on concretes with different CWCPM dosages $(0 \%, 20 \%, 30 \%$, and $40 \%)$, whereas $\mathrm{NaCl}$ solution freeze-thaw test was conducted on concretes with specific CWCPM dosage of $30 \%$, but three different $\mathrm{NaCl}$ solution concentrations were selected, that is, $2.5 \%, 3.5 \%$, and $4.5 \%$. 
TABLE 5: Reference mix ratios of the C20, C25, and C30.

\begin{tabular}{|c|c|c|c|c|c|c|}
\hline \multirow{2}{*}{ Code } & \multirow{2}{*}{ Water cement ratio } & \multirow{2}{*}{ Sand ratio $(\%)$} & \multicolumn{4}{|c|}{ Materials consumption of unit volume concrete $\left(\mathrm{kg} / \mathrm{m}^{3}\right)$} \\
\hline & & & Cement & Aggregate & Sand & Water \\
\hline $\mathrm{C} 20$ & 0.52 & 34 & 228 & 1256 & 647 & 170 \\
\hline $\mathrm{C} 25$ & 0.49 & 33 & 250 & 1252 & 616 & 175 \\
\hline $\mathrm{C} 30$ & 0.45 & 34 & 272 & 1212 & 624 & 175 \\
\hline
\end{tabular}

Using mass loss and relative dynamic modulus to evaluate the antifrost performance of the concrete, these two indices were measured by using electronic scales and DT-W18 dynamic modulus tester.

2.2.2. Microscopic Experiment Methods. In order to investigate the improvement mechanism of CWCPM on performances of the selected concretes, microscopic tests were carried out via XRD, DSC-TG, and Mercury Intrusion Porosimetry (MIP). A fully automatic X-ray diffractometer (D8 ADVANCE) was used in XRD analysis, and DSC-TG analysis was conducted by using Q1000DSC+TG to study the differences of hydration products between cement paste with 30\% CWCPM and 20\% CWBP and reference cement paste $(0 \%$ CWCPM). The water cement ratio of the cement pastes was 0.5 and the curing age was $60 \mathrm{~d}$ in the XRD and DSC-TG tests. After curing, the cement pastes were crushed and immerged in anhydrous ethanol to stop hydration, then grained and sieved through $80 \mu \mathrm{m}$ sieve, and dried to be ready to use. During DSC-TG test, samples were heated from ambient temperature to $900^{\circ} \mathrm{C}$ with a heating rate of $10^{\circ} \mathrm{C} / \mathrm{min}$.

AutoPore IV 9510 was used in the MIP test to investigate the pore structures of the C25 and C30 concretes with and without CWCPM, and the curing age of the specimens was $90 \mathrm{~d}$. After curing, the specimens were cut into small cubes with dimensions of $10 \mathrm{~mm} \times 10 \mathrm{~mm} \times 10 \mathrm{~mm}$, then immerged in anhydrous ethanol to stop hydration, and dried for $24 \mathrm{~h}$ under $105^{\circ} \mathrm{C}$. Three replicate samples were prepared for each type of specimens.

\section{Results and Discussions}

3.1. Effects of CWCPM on Concrete Working Performance. The slumps of the C20, C25, and C30 concretes with different dosages of CWCPM are shown in Figure 4.

In general, the addition of CWCPM reduces the slumps of the C20, C25, and C30 concretes, but different CWCPM's dosages show little difference. This is because the CWBP and mineral powder in the CWCPM can imbibe certain amount of water. On the other hand, the fly ash has a water reduction effect, which can lead to higher slump. As a result, the slumps of the concrete specimens do not change significantly with respect to the CWCPM's dosages.

3.2. Effects of CWCPM on Concrete Mechanical Properties. The $7 \mathrm{~d}$ and $28 \mathrm{~d}$ compressive strengths and the $90 \mathrm{~d}$ flexural strength results of the three selected concretes and the corresponding reference concretes (C20-0\%, C25-0\%, and C30-0\%) are presented in Figures 5 and 6, respectively.

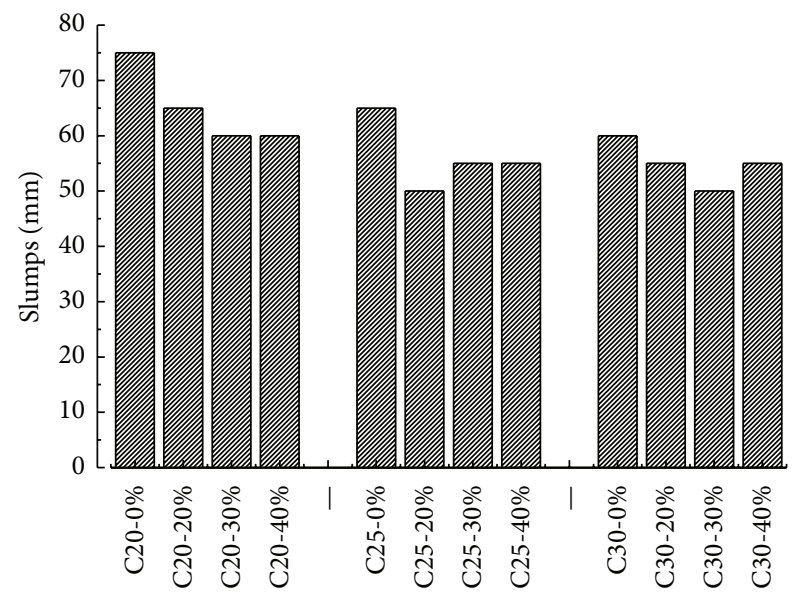

FIGURE 4: Slump test results.

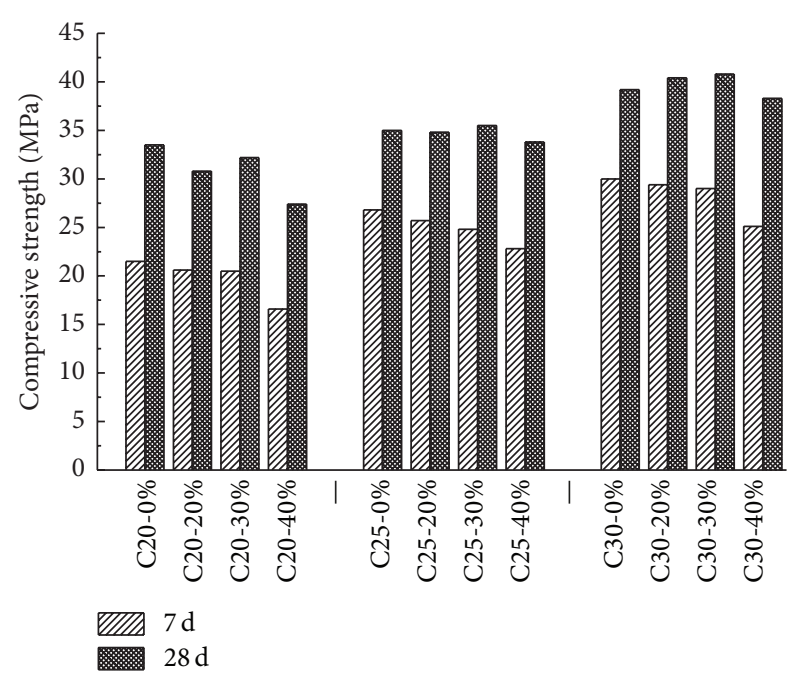

FIGURE 5: Compressive strength test results.

Figure 5 shows that the $7 \mathrm{~d}$ compressive strength decreases with the increase of CWCPM dosage. For instance, when CWCPM dosage is $40 \%$, the $7 \mathrm{~d}$ compressive strengths of C20, C25, and C30 decrease by $22.8 \%, 14.9 \%$, and $16.3 \%$, respectively, compared to their reference concretes. However, the $28 \mathrm{~d}$ compressive strength shows different variations in different concretes. The $28 \mathrm{~d}$ compressive strength of C20 with CWCPM is lower than that of $\mathrm{C} 20-0 \%$, but there is little difference of compressive strengths between C25 with CWCPM and C25-0\%. For C30, the $28 \mathrm{~d}$ compressive strength shows growth when CWCPM dosage is less than 


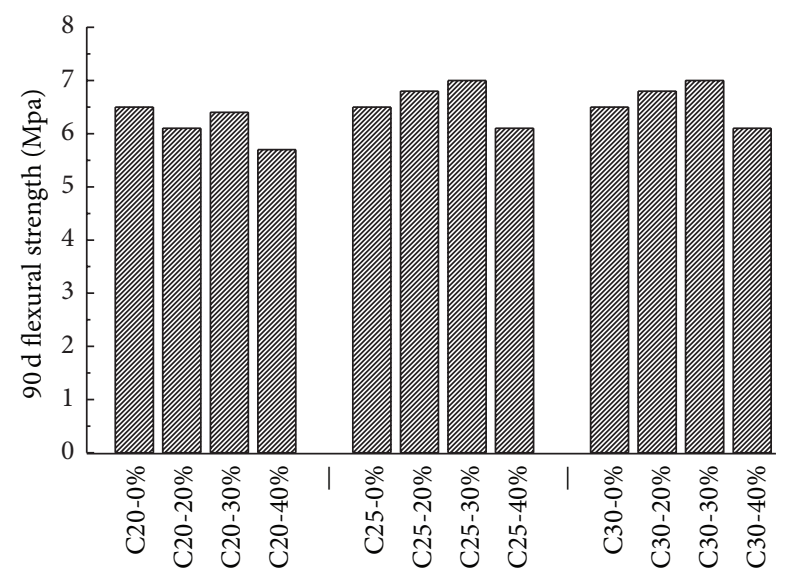

FIGURE 6: Flexural strength test results.

$30 \%$ and then decreases with the increase of CWCPM dosage.

The $90 \mathrm{~d}$ flexural strength of C20 with CWCPM is lower than that of $\mathrm{C} 20-0 \%$, as presented in Figure 6. For C25 and C30, the $90 \mathrm{~d}$ flexural strengths show similar variations, that is, increasing initially and then decreasing. For example, the flexural strengths of C25 and C30 increase by $7.7 \%$ and $14.7 \%$ when CWCPM dosage is $30 \%$ and decrease by $6.2 \%$ and $4.4 \%$ when CWCPM dosage is $40 \%$, respectively, compared to C25$0 \%$ and $\mathrm{C} 30-0 \%$. In general, with the increase of CWCPM dosage, the compressive and flexural strengths of concretes increase first and then decrease and peak at CWCPM dosage of $30 \%$.

The low strength of concrete with CWCPM at early age (7 d) is due to the low early age activities of the components of CWCPM, which lead to less hydration products when CWCPM replaces some portion of cement, resulting in a looser concrete structure. Compared to early age strengths, the different variation of concrete strengths at late age can be explained by the following three reasons. Firstly, CWCPM can prevent cement particles from flocculating, which ensures that the latter distributes uniformly, thus facilitating the hydration process and resulting in a compact structure. Secondly, small CWCPM particles can fill up the available pore spaces between cement particles, which optimizes the particle gradation, leading to a more compact concrete structure. In addition, CWCPM can provide nuclei for cement hydration, which facilitates the hydration process. Finally, $\mathrm{Ca}(\mathrm{OH})_{2}$, a kind of hydration products, and alkaliactivator can maintain an alkaline environment inside the concrete, which ensures the volcanic ash effects of the CWCPM components on perfecting the hydration products, therefore improving the concrete mechanical properties.

In sum, CWCPM can affect concrete strengths positively. The reason is that the components of CWCPM, that is, CWBP, fly ash, mineral powder, and alkali-activator, can contribute to giving positive influences on concrete strength corporately. For example, CWBP particles can fill up the spaces between cement particles, fly ash has good activity at late age, mineral powder has good activity at early age which can compensate the strength reduction of concrete at early age induced by
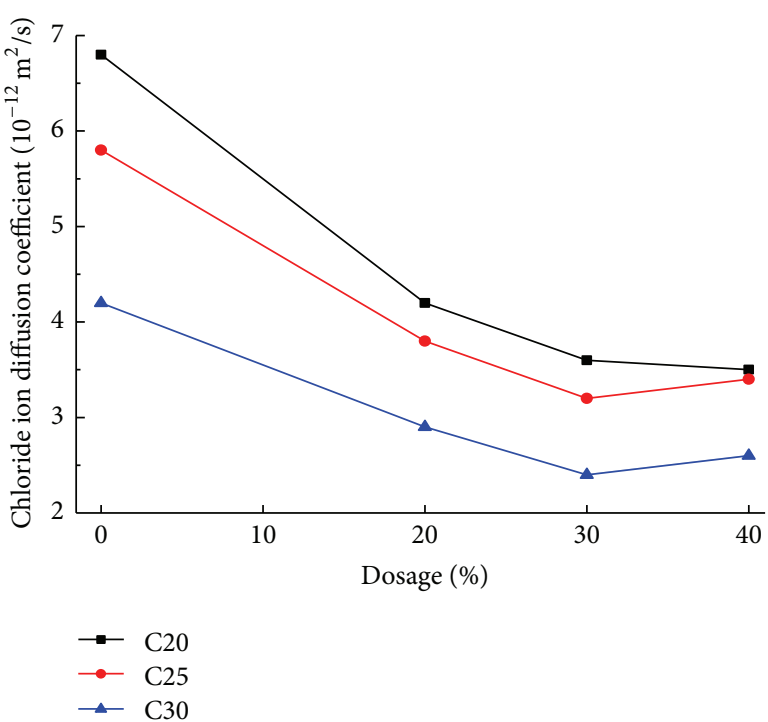

FIGURE 7: The results of antipermeability test.

replacing cement by CWCPM, and finally alkali-activator can provide alkaline environment which could facilitate hydration process.

3.3. Effects of CWCPM on Concrete Antipermeability Performance. The antipermeability is an important property of concrete, which affects the transport mechanisms through the concrete, such as ingress of aggressive gases and solutions. Chloride ion migration coefficient $\left(D_{\mathrm{RCM}}\right)$ is the index for evaluating antipermeability performance, calculated as

$$
\begin{gathered}
D_{\mathrm{RCM}}=\frac{0.0239 \times(273+T) L}{(U-2) t}\left(X_{d}\right. \\
\left.-0.0238 \sqrt{\frac{(273+T) L X_{d}}{U-2}}\right),
\end{gathered}
$$

where $U$ is the absolute value of voltage (V); $T$ is the average temperature $\left({ }^{\circ} \mathrm{C}\right) ; L$ is the specimen thickness $(\mathrm{mm}) ; X_{d}$ is the depth of chloride penetration $(\mathrm{mm}) ; t$ is the time of duration (h). The results of antipermeability test are presented in Figure 7.

From Figure 7, it is clear that replacing some portion of cement by CWCPM can improve the antipermeability performance of concrete significantly, and the best effect is achieved at CWCPM dosage of $30 \%$, at which the chloride ion diffusion coefficients of C20, C25, and C30 decrease by $47.1 \%, 44.8 \%$, and $42.9 \%$, respectively, compared to their corresponding reference concretes.

The reason is that the pozzolanic reaction of CWCPM reduces the content of $\mathrm{Ca}(\mathrm{OH})_{2}$, which has poor performance, and generates low alkalinity calcium silicate hydrate (C-S-H) with a better performance. Meanwhile, CWCPM particles can fill up the gaps between cement particles, as stated before, resulting in higher concrete density and finer pore structures; therefore, the antipermeability performance 


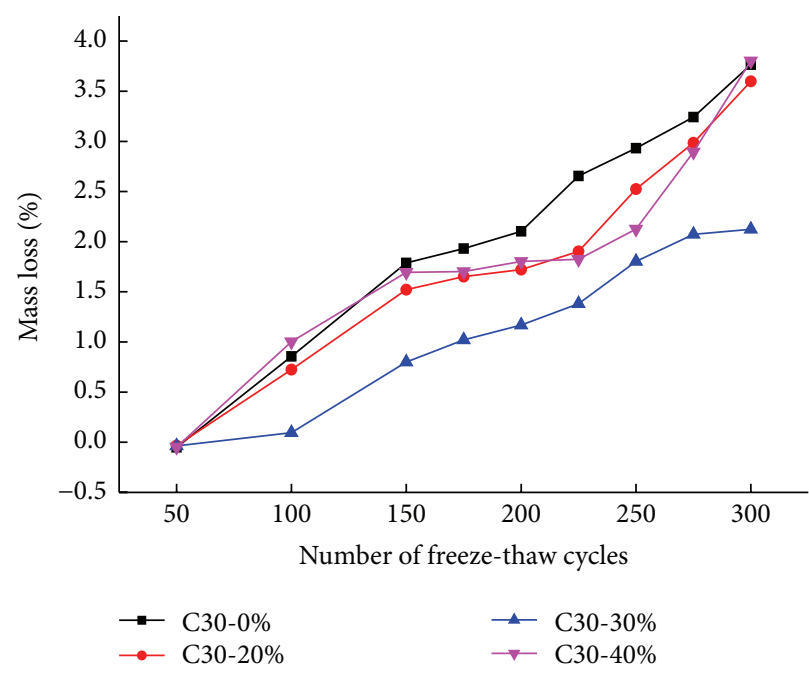

(a) Mass loss

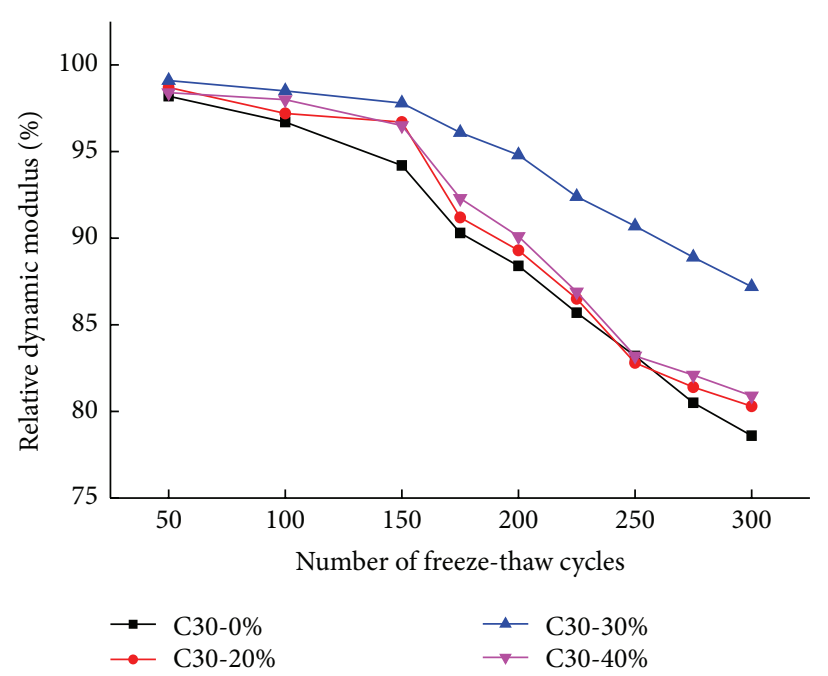

(b) Relative dynamic modulus

Figure 8: The antifrost performance of C30 concrete under water freeze-thaw test.

of concrete is improved. Another reason is that unhydrated CWCPM particles and C-S-H gel can adsorb $\mathrm{Cl}^{-}$to some extent, and Friedel salt is generated through the reaction between $\mathrm{Cl}^{-}$and hydration aluminate or its derivatives, which decreases the $\mathrm{Cl}^{-}$content in the concrete [20,21]. Furthermore, replacing some portion of cement by CWCPM can lower the hydration heat, thus reducing the number of microcracks in the concrete, which improves the antipermeability performance.

Figure 7 also indicates that, at the same dosage of CWCPM, C30 concrete (with water cement ratio of 0.49 ) has the lowest $D_{\mathrm{RCM}}$ value, whereas C20 concrete (with water cement ratio of 0.52 ) has the largest value, which means the antipermeability performance is improved with the decrease of the water cement ratio.

\subsection{Effects of CWCPM on Concrete Antifrost Performance}

3.4.1. Results of Water Freeze-Thaw Test. The results of antifrost performance of C30 concrete under water freezethaw test are graphically presented in Figure 8.

Figures 8(a) and 8(b) show that the mass loss increases and the relative dynamic modulus decreases with the increasing number of freeze-thaw cycles. The antifrost performance of C30 concrete with CWCPM is much better than that of the reference concrete, indicating that CWCPM can also improve the antifrost performance of concrete in addition to mechanical strength and antipermeability performance. This is because the concrete containing CWCPM possesses a more compact microstructure, which reduces the amount of water that can be frozen inside the concrete, and thus the concrete exhibits high resistance to the freeze-thaw damage [22].

Figure 9 shows the water freeze-thaw test results of different strength concretes with the same CWCPM dosage (i.e., 30\%).

Under the same dosage of CWCPM, Figure 9 indicates that C30 has the best antifrost performance, whereas C20 has the worst, which means that the antifrost performance is also related to the concrete strength and higher strength of the concrete yields stronger resistance to freeze and thaw damage.

3.4.2. Results of $\mathrm{NaCl}$ Solution Freeze-Thaw Test. The $\mathrm{NaCl}$ solution freeze-thaw tests were conducted on C30 concrete with 30\% CWCPM (i.e., C30-30\%) under different concentrations of $\mathrm{NaCl}$ solution. Figure 10 shows the C30-30\% specimens after tests and Figure 11 presents the mass loss and relative dynamic modulus of the specimens.

From Figure 10, it can be seen that, after 50 cycles, the specimen under water freeze-thaw condition still has smooth surface, whereas the surfaces of the specimens under $\mathrm{NaCl}$ solution freeze-thaw condition become rough, indicating the surfaces are eroded by the $\mathrm{NaCl}$ solution. When the number of freeze-thaw cycles reaches 100, the specimen under water freeze-thaw condition only shows slightly rough surface; however, serious surface spalling and a large number of grooves can be observed in terms of the specimens under $\mathrm{NaCl}$ solution freeze-thaw condition.

As shown in Figure 11, compared to water freeze-thaw cycle, $\mathrm{NaCl}$ solution freeze-thaw cycle has larger damage to the concrete. Furthermore, the $\mathrm{NaCl}$ solution concentration of $3.5 \%$ exerts the most negative influence on the antifrost performance of concrete, followed by $4.5 \%$ and then $2.5 \%$, which indicates that higher $\mathrm{NaCl}$ solution concentration does not mean more serious freeze-thaw damage [23].

Generally speaking, $\mathrm{NaCl}$ solution has both positive and negative influences on the antifrost performance of concrete. On one hand, the existence of the $\mathrm{NaCl}$ solution can decrease the freezing point of the water inside concrete, and the anticompression property of the $\mathrm{NaCl}$ solution is better than that of pure water when frozen; this exerts positive impact on the antifrost performance of concrete. On the other hand, negative pressure inside concrete occurs due to the volume reductions of pore solution and pore air when frozen; this negative pressure becomes even larger when $\mathrm{NaCl}$ solution 


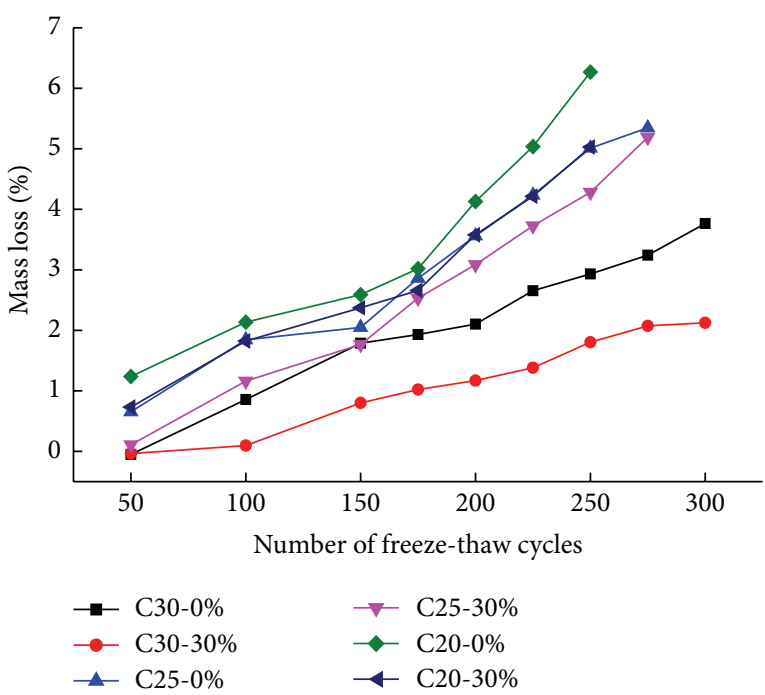

(a) Mass loss

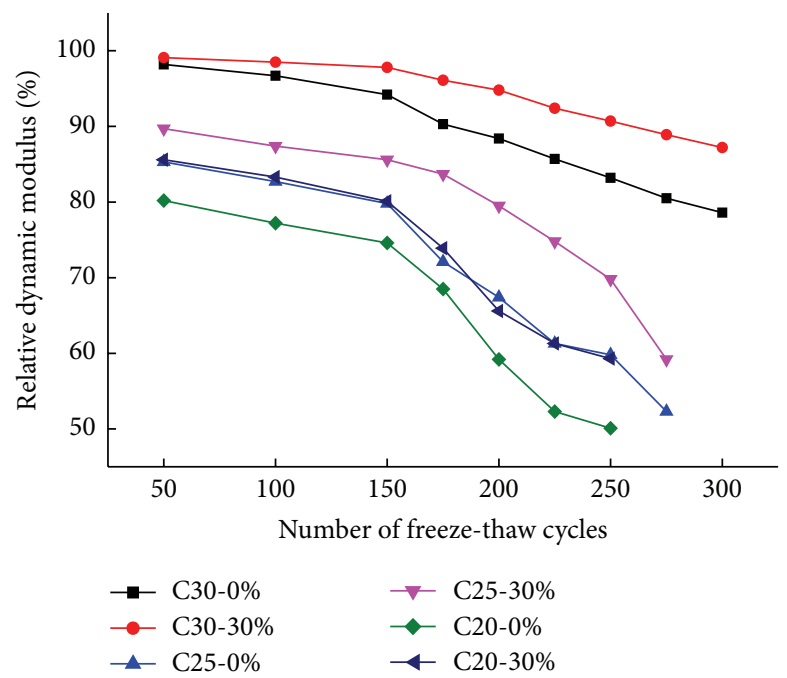

(b) Relative dynamic modulus

FIGURE 9: The antifrost performances of different strength concretes under water freeze-thaw test.

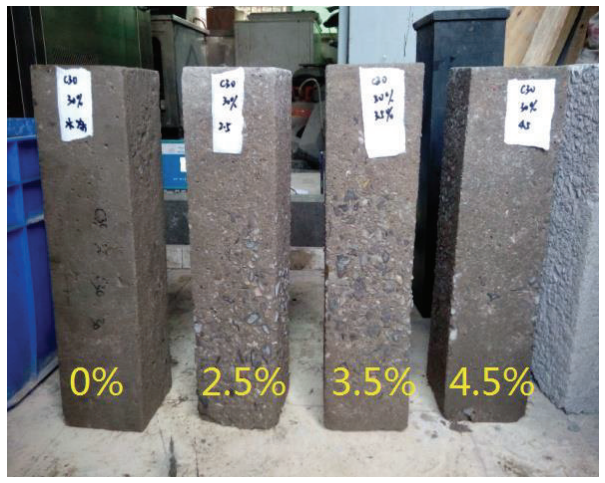

(a) After 50 cycles

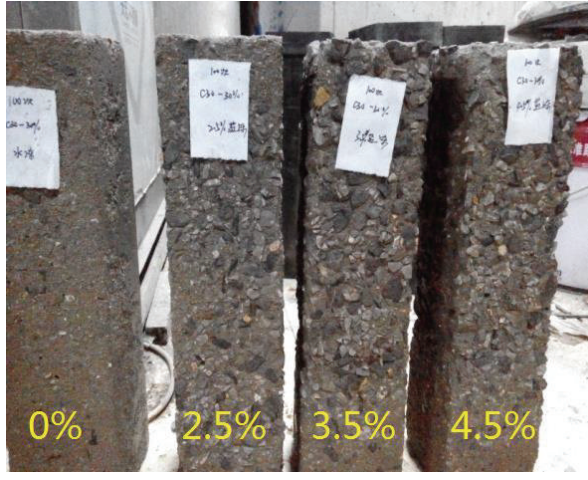

(b) After 100 cycles

Figure 10: The C30-30\% specimens after 50 and 100 salt solution freeze-thaw cycles. Note: from left to right, the concentrations of the NaCl solutions were $0 \%$ (i.e., under water freeze-thaw condition, for comparison), $2.5 \%, 3.5 \%$, and $4.5 \%$, respectively.

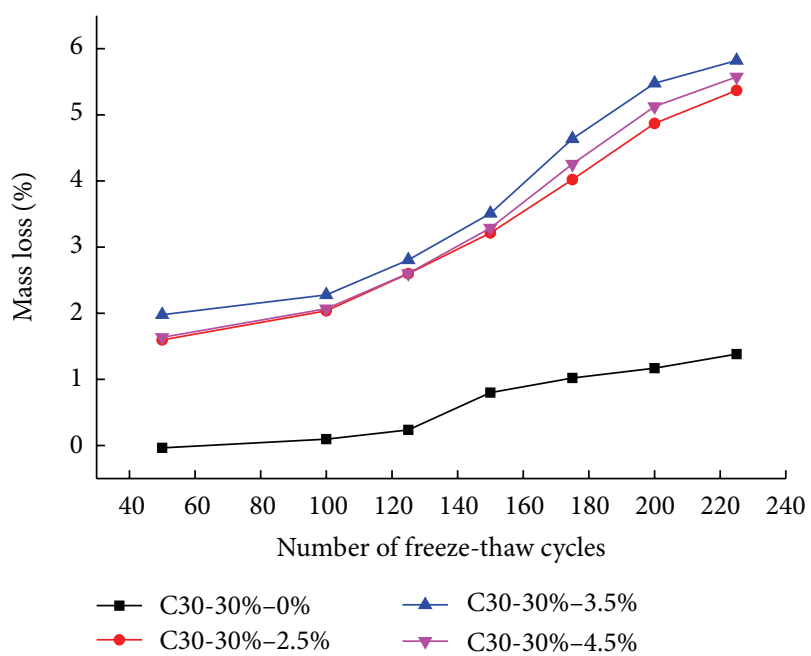

(a) Mass loss

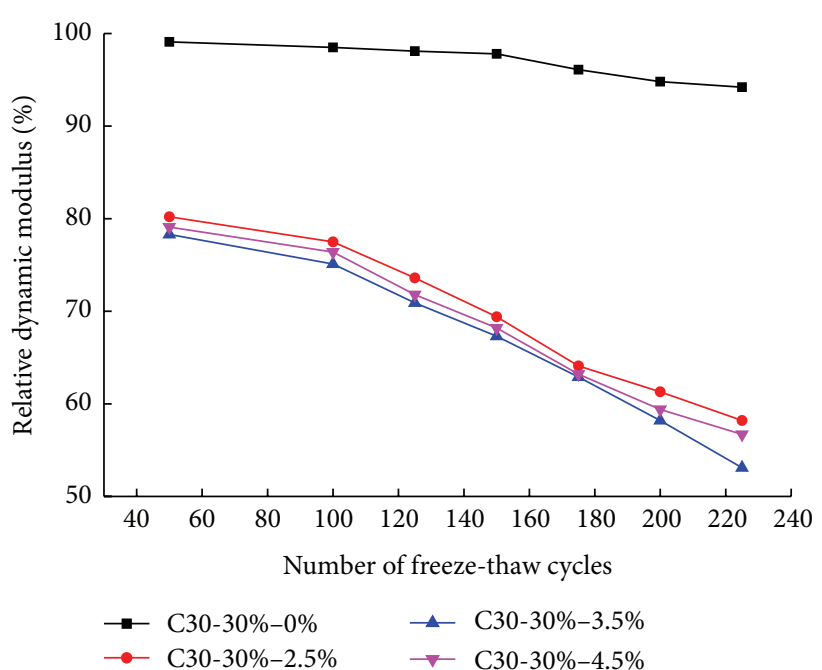

(b) Relative dynamic modulus

FIGURE 11: The antifrost performance of $\mathrm{C} 30-30 \%$ concrete under $\mathrm{NaCl}$ solution freeze-thaw test. 


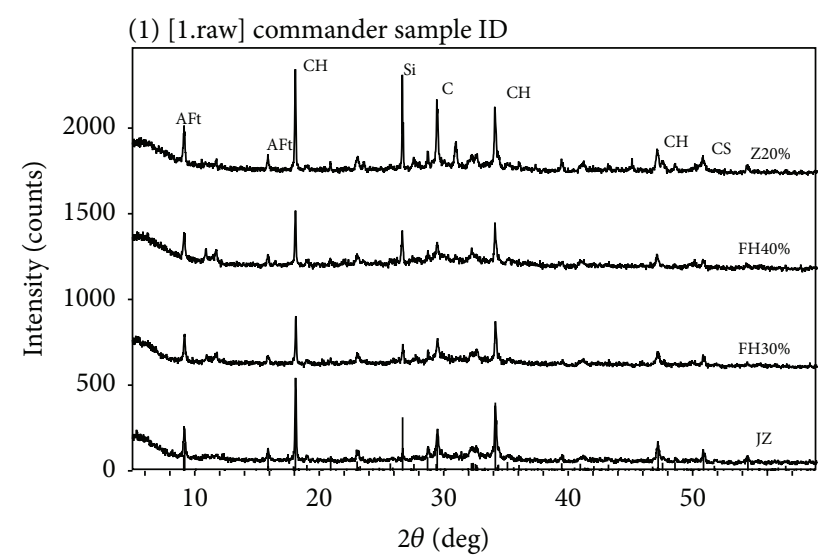

FIGURE 12: The results of XRD test. Note: Aft: Ettringite; $\mathrm{CH}$ : $\mathrm{Ca}(\mathrm{OH})_{2} ; \mathrm{Si}: \mathrm{SiO}_{2} ; \mathrm{C}: \mathrm{CaCO}_{3} ; \mathrm{CS}: \mathrm{C}_{2} \mathrm{~S}$; JZ: control specimen; Z20\%: specimen with $20 \mathrm{wt} \%$ CWBP; FH30\% and $\mathrm{FH} 40 \%$ : specimens with $30 \mathrm{wt} \%$ and $40 \mathrm{wt} \%$ CWCPM, respectively.

exists, increasing linearly with the increase of $\mathrm{NaCl}$ concentration. The negative pressure enlarges the amount of solution infiltrating into the concrete and migrating to surrounding pores under ice-formation pressure, thus significantly increasing the degree of saturation of the concrete, which will result in larger negative pressure during next freezethaw cycle. In addition to the negative pressure, osmotic pressure and crystallization pressure due to the existence of $\mathrm{NaCl}$ solution also aggravate the antifrost performance of the concrete. In general, the negative influence of $\mathrm{NaCl}$ solution on the antifrost performance of the concrete is more dominant than the positive influence; therefore, serious decline of the antifrost performance can be observed under $\mathrm{NaCl}$ solution freeze-thaw condition.

3.5. Effects of CWCPM on Concrete Microstructures. The XRD, DSC-TG, and MIP tests were used to investigate the influences of different powder materials on the hydration products and pore structures of the concretes.

3.5.1. XRD Test Results. XRD analysis was used to characterize the crystallographic structures of the hydration products. The cement paste specimens were prepared with pure cement (control specimen), $20 \mathrm{wt} \%$ CWBP, $30 \mathrm{wt} \%$ CWCPM, and $40 \mathrm{wt} \%$ CWCPM, respectively. The results are graphically presented in Figure 12.

Figure 12 shows that the cement paste with CWBP or CWCPM does not generate new types of hydration products compared to the control specimen. The main crystalline phases in all the cement pastes are $\mathrm{Aft}, \mathrm{Ca}(\mathrm{OH})_{2}, \mathrm{CaCO}_{3}$, and part of unhydrated $\mathrm{C}_{2} \mathrm{~S}$ and $\mathrm{SiO}_{2}$. However, the characteristic values of diffraction peaks are different, indicating that CWBP and CWCPM can change the quantities of the hydration products. For example, due to its pozzolanic effect, CWCPM significantly decreases the diffraction peak of $\mathrm{Ca}(\mathrm{OH})_{2}$ that has poor performance, generating the C$\mathrm{S}$-H gel with low alkalinity but better performance than $\mathrm{Ca}(\mathrm{OH})_{2}$, and thus improves the concrete compactness and

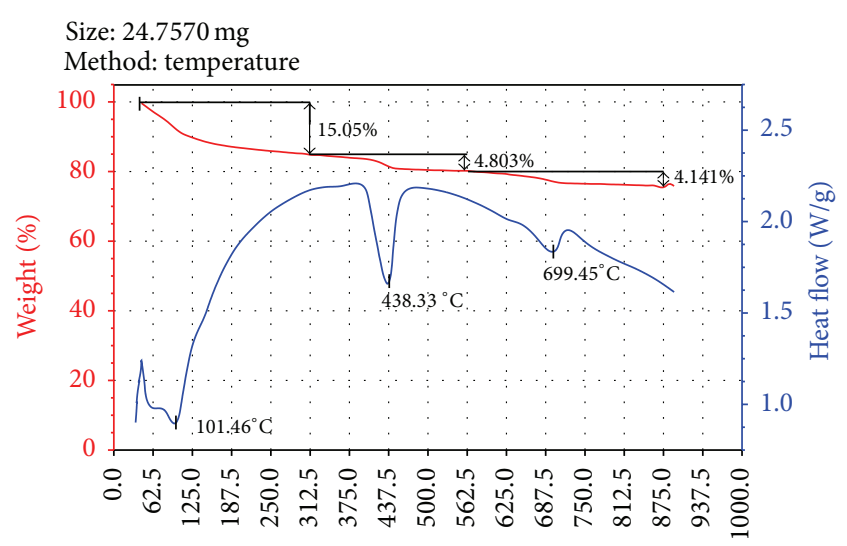

Exothermic peak is upward

Temperature $\left({ }^{\circ} \mathrm{C}\right)$

Universal V4.4A

TA instruments

FIGURE 13: The DSC-TG curves of pure cement paste.

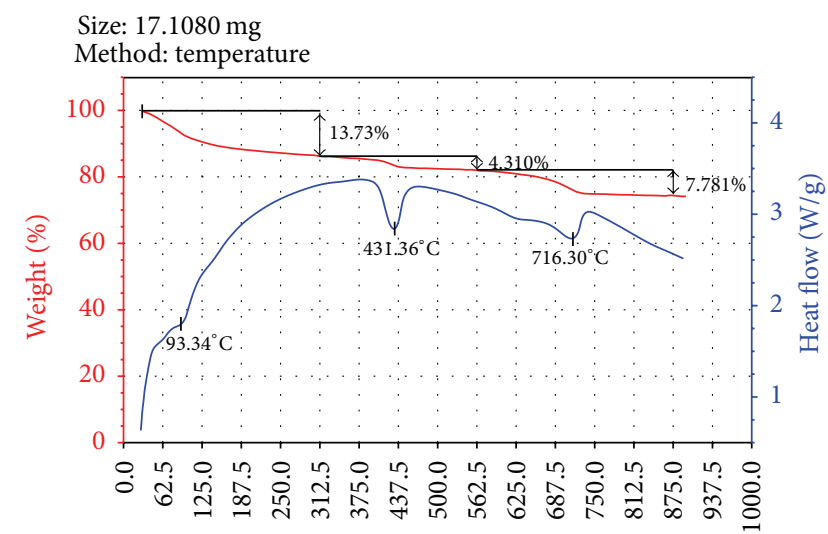

Exothermic peak is upward

Temperature $\left({ }^{\circ} \mathrm{C}\right)$

Universal V4.4A

TA instruments

FIGURE 14: The DSC-TG curves of cement paste with $20 \mathrm{wt} \%$ CWBP.

lowers solution permeability inside the concrete, yielding better antipermeability and antifrost performances. However, it should be noted that the extent of improvement is larger when CWCPM has a dosage of $30 \%$ compared to $40 \%$. Cement paste with $20 \mathrm{wt} \%$ CWBP (i.e., Z20\%) has a high value of diffraction peak of $\mathrm{SiO}_{2}$, this is because only $6 \%$ $\mathrm{SiO}_{2}$ in CWBP is active (although the total amount of $\mathrm{SiO}_{2}$ in CWBP is $49.3 \%$ ), and thus most $\mathrm{SiO}_{2}$ does not take part in the hydration reaction, resulting in high value of diffraction peak of $\mathrm{SiO}_{2}$. In addition, the very low value of diffraction peak of $\mathrm{C}_{2} \mathrm{~S}$ in all types of specimens is due to the curing age (60 d), when most $\mathrm{C}_{2} \mathrm{~S}$ has contributed to the hydration reaction.

3.5.2. DSC-TG Test Results. The DSC-TG test was used to quantitatively analyze the influences of CWCPM and CWBP on the cement hydration products. Figures 13-15 show the test results of pure cement paste (control specimen, JZ), cement paste with $20 \mathrm{wt} \%$ CWBP (Z20\%), and cement paste with $30 \mathrm{wt} \%$ CWCPM (FH30\%), respectively.

As shown in Figures 13-15, the DSC-TG curves of cement pastes with CWBP and CWCPM show the same variations as 
TABLE 6: The results of MIP test of C25 and C30.

\begin{tabular}{|c|c|c|c|c|c|}
\hline & \multirow{2}{*}{ Total void area $/ \mathrm{m}^{2} / \mathrm{g}$} & \multirow{2}{*}{ The average pore diameter/nm } & \multicolumn{2}{|c|}{ The median pore diameter/ $\mu \mathrm{m}$} & \multirow{2}{*}{ Porosity $/ \%$} \\
\hline & & & Volume & Area & \\
\hline C25-0\% & 1.725 & 53.5 & 175.0 & 14.0 & 5.9580 \\
\hline $\mathrm{C} 25-30 \%$ & 7.910 & 34.3 & 73.0 & 13.3 & 14.6624 \\
\hline C30-0\% & 5.059 & 52.6 & 96.2 & 26.7 & 14.8215 \\
\hline C30-30\% & 4.931 & 39.4 & 81.9 & 14.7 & 9.0298 \\
\hline \multicolumn{6}{|c|}{ Pore size distribution/\% } \\
\hline & $<20 \mathrm{~nm}$ & $20 \sim 50 \mathrm{~nm}$ & $50 \sim 100 \mathrm{~nm}$ & $100 \sim 200 \mathrm{~nm}$ & $>200 \mathrm{~nm}$ \\
\hline C25-0\% & 12.46 & 12.17 & 12.62 & 14.53 & 48.22 \\
\hline $\mathrm{C} 25-30 \%$ & 19.33 & 19.48 & 21.29 & 13.83 & 26.07 \\
\hline C $30-0 \%$ & 9.07 & 20.7 & 19.73 & 26.31 & 24.2 \\
\hline C30-30\% & 16.55 & 17.64 & 21.27 & 13.41 & 31.12 \\
\hline
\end{tabular}

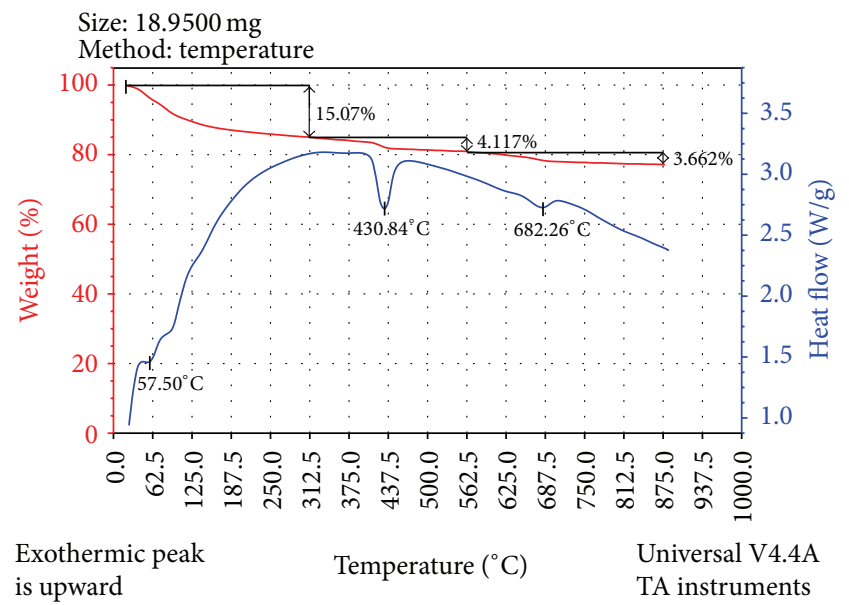

FIGURE 15: The DSC-TG curves of cement paste with $30 \mathrm{wt} \%$ CWCPM.

the control specimen, but somewhat different locations and values of the endothermic peaks can be observed. For each type of the specimens, the locations of the endothermic peaks are around $100^{\circ} \mathrm{C}, 430^{\circ} \mathrm{C}$, and $680^{\circ} \mathrm{C}$, which correspond to the dehydration of cement hydration products, dehydration of $\mathrm{Ca}(\mathrm{OH})_{2}$, and decomposition of $\mathrm{CaCO}_{3}$ giving rise to $\mathrm{CO}_{2}$, respectively. The DSC curves indicate that the peak temperature, starting temperature, peak height, and area of the endothermic peaks of the cement pastes with CWBP and CWCPM are lower than those of the pure cement paste; this is because the existence of CWBP or CWCPM improves the compactness of the cement paste and thus alters its thermal conductivity.

From the TG curves, it is known that mass loss of the cement paste with $30 \mathrm{wt} \%$ CWCPM is slightly higher than that of the pure cement paste within temperature range of $50 \sim 300^{\circ} \mathrm{C}$ (which means higher $\mathrm{C}-\mathrm{S}-\mathrm{H}$ content) but $14.3 \%$ lower within temperature range of $400 \sim 500^{\circ} \mathrm{C}$ (which means lower $\mathrm{Ca}(\mathrm{OH})_{2}$ content). This shows that $\mathrm{Ca}(\mathrm{OH})_{2}$ can not only stimulate the pozzolanic effect of CWCPM as activator, but also react with CWCPM generating C-S-H that has low
$\mathrm{Ca} / \mathrm{Si}$ ratio; therefore, the content of $\mathrm{C}-\mathrm{S}-\mathrm{H}$ increases and that of $\mathrm{Ca}(\mathrm{OH})_{2}$ reduces.

In terms of cement paste with $20 \mathrm{wt} \%$ CWBP, its mass losses within temperature ranges of $50 \sim 300^{\circ} \mathrm{C}$ and $400 \sim$ $500^{\circ} \mathrm{C}$ are $8.8 \%$ and $10.3 \%$ lower than those of the pure cement paste, respectively, indicating the reductions of $\mathrm{C}-\mathrm{S}$ $\mathrm{H}$ and $\mathrm{Ca}(\mathrm{OH})_{2}$ due to the existence of CWBP. However, the reason for the reductions, which is different from the case of CWCPM, is that CWBP has low activity and thus decreases the hydration products, resulting in low contents of C-S-H and $\mathrm{Ca}(\mathrm{OH})_{2}$.

The XRD and DSC-TG test results show that CWCPM can positively influence the cement hydration reaction due to its pozzolanic effect, improve the hydration products, and produce good interfacial bond between aggregates and cement paste by forming low alkalinity C-S-H. It is well known that C-S-H gel contributes to the strength and durability of concrete [24]. Moreover, the good filling effect of unhydrated CWCPM particles can improve the compactness of the concrete, thus increasing the concrete strength and antipermeability and antifrost performances.

3.5.3. MIP Test Results. The pore structure parameters and pore size distributions of C25 and C30 with and without CWCPM (i.e., $30 \mathrm{wt} \%$ and $0 \mathrm{wt} \%$ ) are tabulated in Table 6.

CWCPM affects the pore structure parameters of C25 and C30 differently, as presented in Table 6. For the C25 concrete with $30 \mathrm{wt} \%$ CWCPM (C25-30\%), the porosity and total void area are significantly higher than those of C25 without CWCPM (C25-0\%), but the average pore diameter and median pore diameter show opposite variation, which indicates that the pore structure of the $\mathrm{C} 25$ concrete is refined. In terms of the C30 concrete, however, all the pore structure parameters decline, and the average pore diameter and the porosity of the C30 concrete with $30 \mathrm{wt} \%$ CWCPM (C30$30 \%$ ) decrease by $25.1 \%$ and $39.1 \%$, respectively, compared to its reference concrete (C30-0\%).

The macroscopic tests done previously have shown that CWCPM has positive impacts on the antipermeability and antifrost performances of C25 and C30, which illustrates that the pore structure parameter is not the only factor that determines the concrete performance, which is also related 
to the pore size distribution. It can be concluded from the pore size distributions in Table 6 that, generally, CWCPM can increase the amount of small pores $(\leqq 100 \mathrm{~nm})$ while decreasing the amount of larger pores $(>100 \mathrm{~nm})$; therefore, reasonable pore size distribution is obtained compared to the reference concretes. Specifically, incorporating CWCPM into C25 and into C30 increases the quantities of capillary pores ( $\leqq 50 \mathrm{~nm}$ ), which have well-recognized function of improving the concrete strength and other performances, by $57.6 \%$ and $14.8 \%$, respectively, compared to the concretes without CWCPM. This shows that the incorporation of CWCPM can effectively increase the amount of the capillary pores to improve concrete durability [25].

CWCPM improving the concrete pore structures can be attributed to the following: (1) CWCPM facilitates forming low alkalinity $\mathrm{C}-\mathrm{S}-\mathrm{H}$ gel and decreasing the content of $\mathrm{Ca}(\mathrm{OH})_{2}$ due to its pozzolanic effect and large pores inside the concrete can be filled by the fine C-S-H gel and unhydrated CWCPM particles, and (2) by absorbing some portion of free-water inside the concrete, CWCPM reduces the amount of pores generated by free-water evaporation.

The refinement of the pore structure has the following impacts on the concrete performances: (1) small pores can lower the pore connectivity inside the concrete, block the seepage channel for free-water, and reduce its diffusion rate, thus improving the antipermeability of the concrete; (2) generally, smaller pore size means lower freezing point of pore solution, which can reduce the hydrostatic pressure and osmotic pressure in the capillary pores, resulting in less damage to the concrete due to icing expansion and improving the concrete antifrost performance; and (3) the content of the free-water that can be frozen decreases with the refinement of the pore structure, and reasonable pore size distribution can ensure less stress concentration and strengthen the concrete.

\section{Conclusions}

This work was conducted to explore the feasibility of applying CWCPM in the small-scale prefabricated concretes. The laboratory evaluation of the working performance, mechanical strengths, and antipermeability and antifrost performances of the selected concretes as well as microscopic analyses was carried out. Based on the laboratory tests and analyses, the main conclusions drawn from this study are as follows:

(1) The $7 \mathrm{~d}$ compressive strength of the concrete with CWCPM decreases, but there are no substantial differences of the $28 \mathrm{~d}$ compressive and $90 \mathrm{~d}$ flexural strengths between the concretes with and without CWCPM. The optimum dosage of CWCPM is $30 \%$.

(2) The chloride ion migration coefficients of the concretes decline with the existence of CWCPM, which indicates that CWCPM can lower the chloride ion penetrability inside the concretes, therefore reducing the risk of chloride-induced corrosion of the concrete, but further electrochemical investigation is needed on this issue.
(3) Both CWCPM and the $\mathrm{NaCl}$ solution concentration have great impacts on the concrete antifrost performance. Due to its filling and pozzolanic effects, CWCPM can positively improve the antifrost performance of the concrete. As in comparison to the water freeze-thaw test, the mass and relative dynamic modulus of the concrete specimens decrease rapidly under $\mathrm{NaCl}$ solution conditions, suggesting that coupling of freeze-thaw and salt erosion can exert significant damage to the concrete.

(4) As evidenced by the microscopic tests, CWCPM contributes to generating low alkalinity C-S-H gel with good performance, which can densify the concrete structure by filling up pores. Moreover, CWCPM can decrease the content of $\mathrm{Ca}(\mathrm{OH})_{2}$ which has an obvious orientation and low intensity. Furthermore, the pore size distribution of the concrete becomes more reasonable after CWCPM is added, meaning great improvement of the concrete durability.

(5) The presented study provides evidence for supporting the feasibility and priority of using CWCPM in concrete industry because of its cost-effective and environmentally friendly characteristics, and further studies, however, are needed to investigate its field performances.

\section{Disclosure}

This paper presents a comprehensive study on evaluating the potential use of construction waste composite powder material (CWCPM) as cementitious material in cement concrete. The results are encouraging and show that the CWCPM can improve the strength and durability of cement concrete. This provides theoretical and practical bases for effectively recycling construction wastes, both in China and across the world.

\section{Competing Interests}

The authors do not have competing interests regarding the publication of this paper.

\section{Acknowledgments}

The writers wish to acknowledge the financial supports of this research by the Construction Science and Technology Project of Ministry of Transport of China (no. 2013318J16490) and the Fundamental Research Funds for Central Universities (no. 310821165012).

\section{References}

[1] http://www.fqwzyhlm.org/index.php?m=content\&c=index\& $\mathrm{a}=$ show\&catid $=31$ \&id $=64$.

[2] D. Xuan, Environmental performance analysis of construction waste regeneration [M.S. thesis], Shandong University of Science and Technology, Qingdao, China, 2011.

[3] Z. Li, Properties of concrete with recycled clay-brick-powder [M.S. thesis], Shandong University, Jinan, China, 2012. 
[4] X. Ma and Z. Wang, "Effect of ground waste concrete powder on cement properties," Advances in Materials Science and Engineering, vol. 2013, Article ID 918294, 5 pages, 2013.

[5] L. Turanli, F. Bektas, and P. J. M. Monteiro, "Use of ground clay brick as a pozzolanic material to reduce the alkali-silica reaction," Cement and Concrete Research, vol. 33, no. 10, pp. 15391542, 2003.

[6] A. Chakchouk, B. Samet, and T. Mnif, "Study on the potential use of Tunisian clays as pozzolanic material," Applied Clay Science, vol. 33, no. 2, pp. 79-88, 2006.

[7] B. Samet and M. Chaabouni, "Characterization of the Tunisian blast-furnace slag and its application in the formulation of a cement," Cement and Concrete Research, vol. 34, no. 7, pp. 11531159, 2004.

[8] F. Debieb and S. Kenai, "The use of coarse and fine crushed bricks as aggregate in concrete," Construction and Building Materials, vol. 22, no. 5, pp. 886-893, 2008.

[9] F. Bektas, K. Wang, and H. Ceylan, "Effects of crushed clay brick aggregate on mortar durability," Construction and Building Materials, vol. 23, no. 5, pp. 1909-1914, 2009.

[10] A. Naceri and M. C. Hamina, "Use of waste brick as a partial replacement of cement in mortar," Waste Management, vol. 29, no. 8, pp. 2378-2384, 2009.

[11] T. Kavas and A. Olgun, "Properties of cement and mortar incorporating marble dust and crushed brick," CeramicsSilikaty, vol. 52, no. 1, pp. 24-28, 2008.

[12] S. Wild, "Observations on the use of ground waste clay brick as a cement replacement material," Building Research \& Information, vol. 24, no. 1, pp. 35-40, 1996.

[13] M.-Z. Chen, J.-T. Lin, S.-P. Wu, and C.-H. Liu, "Utilization of recycled brick powder as alternative filler in asphalt mixture," Construction and Building Materials, vol. 25, no. 4, pp. 15321536, 2011.

[14] M. O'Farrell, S. Wild, and B. B. Sabir, "Pore size distribution and compressive strength of waste clay brick mortar," Cement and Concrete Composites, vol. 23, no. 1, pp. 81-91, 2001.

[15] K.-L. Lin, H.-H. Wu, J.-L. Shie, C.-L. Hwang, and A. Cheng, "Recycling waste brick from construction and demolition of buildings as pozzolanic materials," Waste Management and Research, vol. 28, no. 7, pp. 653-659, 2010.

[16] S. Wild, A. Gailius, H. Hansen et al., "Pozzolanic properties of a variety of European clay bricks," Building Research \& Information, vol. 25, no. 3, pp. 170-175, 1997.

[17] Q. Liu, T. Tong, S. Liu, D. Yang, and Q. Yu, "Investigation of using hybrid recycled powder from demolished concrete solids and clay bricks as a pozzolanic supplement for cement," Construction and Building Materials, vol. 73, pp. 754-763, 2014.

[18] L. Zhang, "Production of bricks from waste materials-a review," Construction and Building Materials, vol. 47, pp. 643655, 2013.

[19] "Standard for test methods of long-term performance and durability of ordinary concrete," GB/T 50082-2009, China, 2009.

[20] G. Peiwei, D. Min, and F. Naiqian, "The influence of superplasticizer and superfine mineral powder on the flexibility, strength and durability of HPC," Cement and Concrete Research, vol. 31, no. 5, pp. 703-706, 2001.

[21] F. Leng, N. Feng, and X. Lu, "Experimental study on the properties of resistance to diffusion of chloride ions of fly ash and blast furnace slag concrete," Cement and Concrete Research, vol. 30, no. 6, pp. 989-992, 2000.
[22] M. Jalal, "Durability enhancement of concrete by incorporating titanium dioxide nanopowder into binder," Journal of American Science, vol. 8, no. 4, pp. 289-294, 2012.

[23] S. Lindmark, Mechanisms of salt frost scaling on portland cement-bound materials: studies and hypothesis [Ph.D. thesis], Lund University, Lund, Sweden, 1998.

[24] P. K. Mehta and P. J. M. Monteiro, Concrete: Microstructure, Properties, and Materials, McGraw-Hill, New York, NY, USA, 2006.

[25] H. Uchikawa, S. Hanehara, and H. Hirao, "Influence of microstucture on the physical properties of concentrate prepared by substituting mineral powder for part of fine aggregate," Cement and Concrete Research, vol. 26, no. 1, pp. 101-111, 1996. 

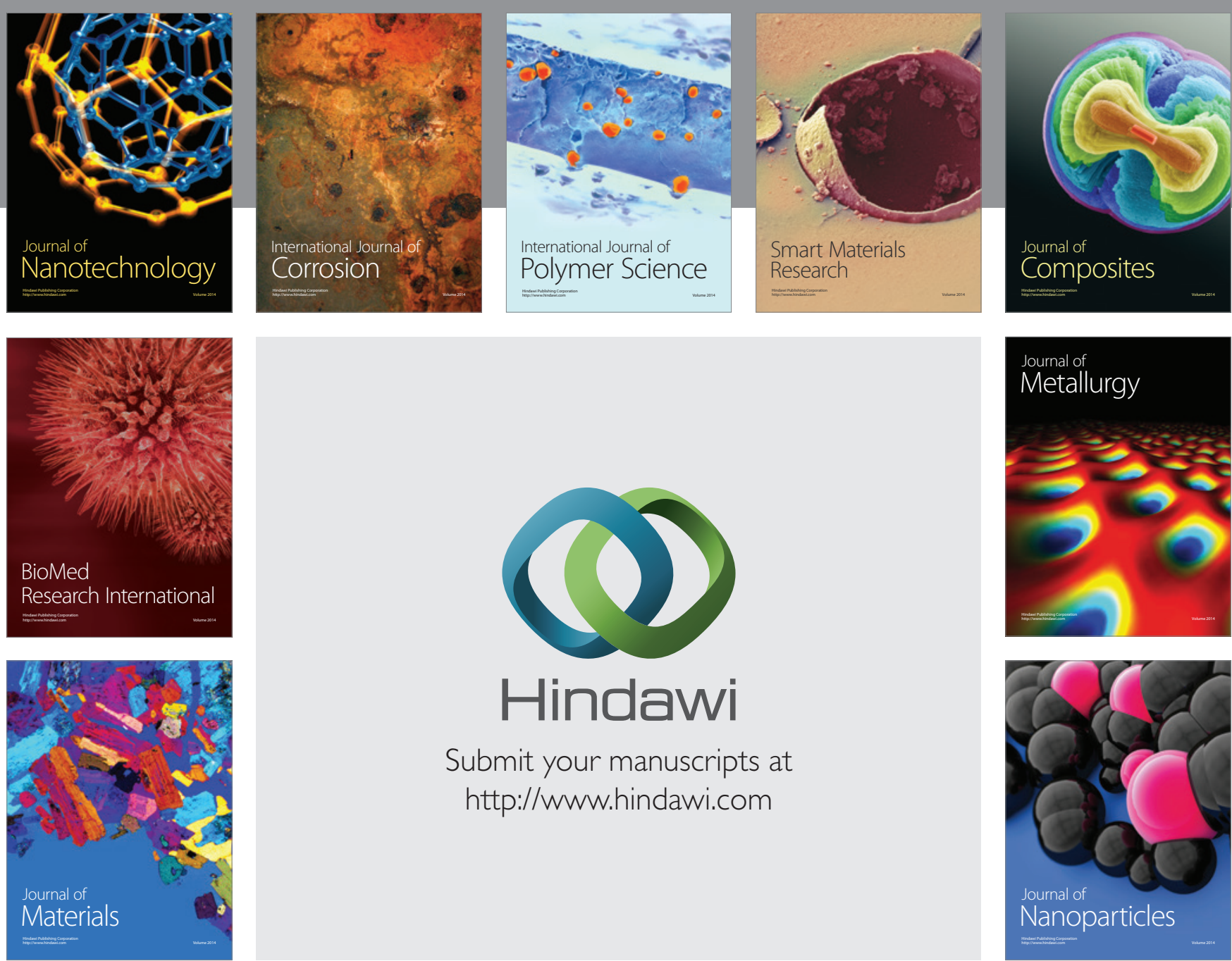

\section{Hindawi}

Submit your manuscripts at

http://www.hindawi.com

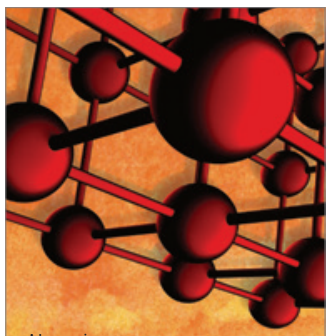

Materials Science and Engineering
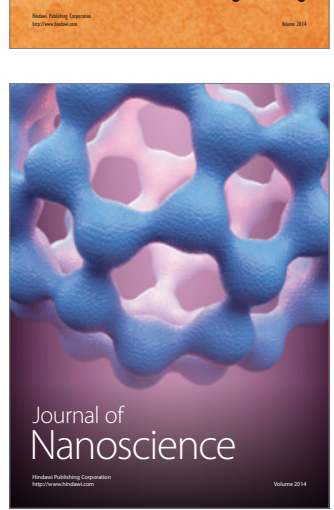
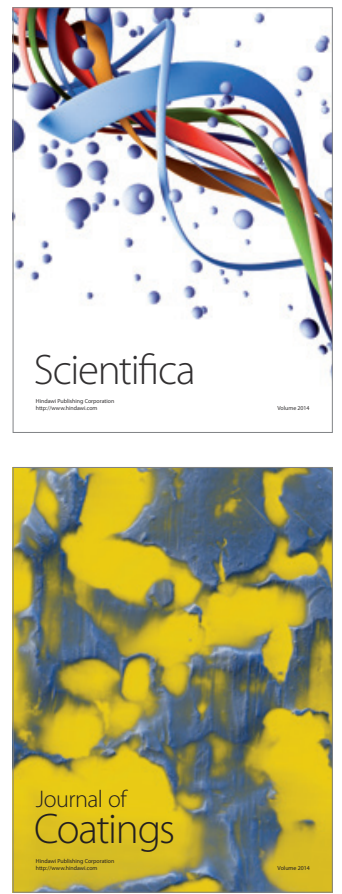
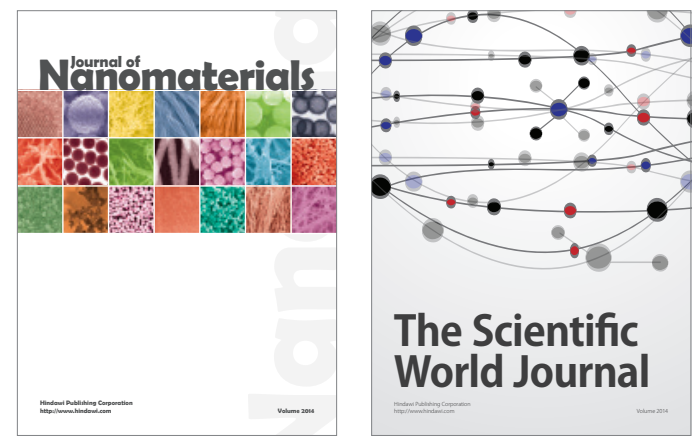

The Scientific World Journal
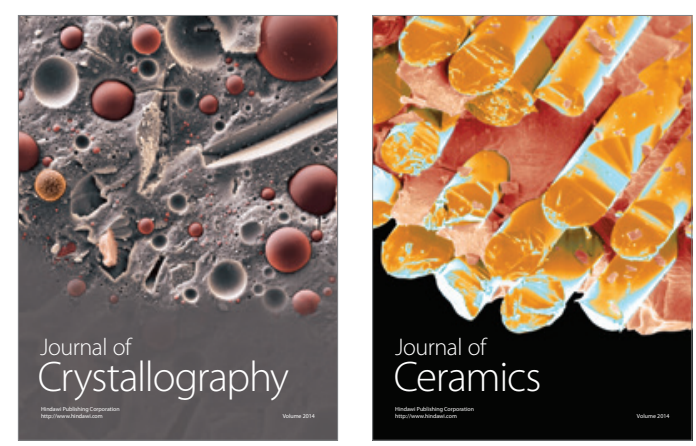
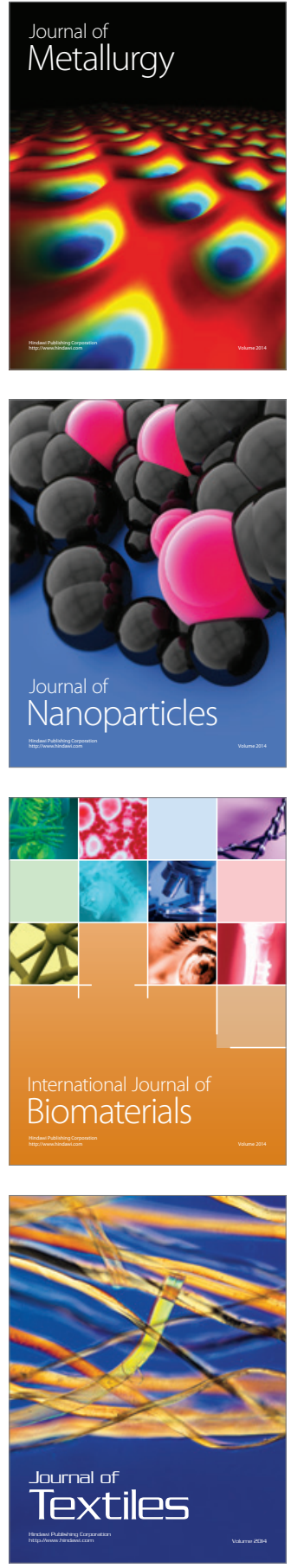